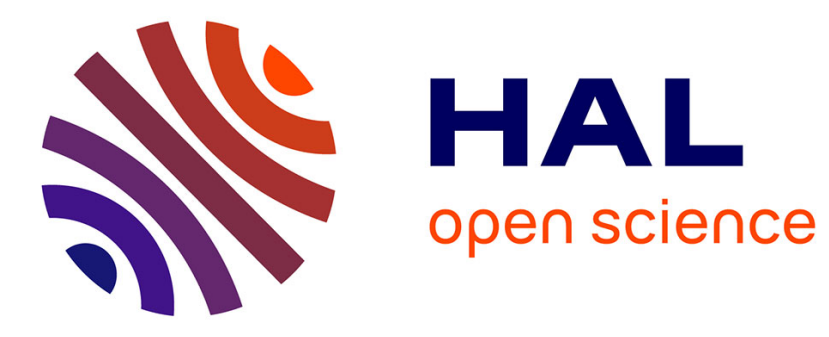

\title{
Magnetic ordering in the new ternary stannide U3Rh4Sn13
}

François Mirambet, Bernard Chevalier, Léopold Fournès, Marie Jeanne J Besnus, Pierre Gravereau, Jean Etourneau

\section{- To cite this version:}

François Mirambet, Bernard Chevalier, Léopold Fournès, Marie Jeanne J Besnus, Pierre Gravereau, et al.. Magnetic ordering in the new ternary stannide U3Rh4Sn13. Journal of Magnetism and Magnetic Materials, 1993, 118 (1-2), pp.187-192. 10.1016/0304-8853(93)90176-3 . hal-03211516

\section{HAL Id: hal-03211516 https://hal.science/hal-03211516}

Submitted on 28 Apr 2021

HAL is a multi-disciplinary open access archive for the deposit and dissemination of scientific research documents, whether they are published or not. The documents may come from teaching and research institutions in France or abroad, or from public or private research centers.
L'archive ouverte pluridisciplinaire HAL, est destinée au dépôt et à la diffusion de documents scientifiques de niveau recherche, publiés ou non, émanant des établissements d'enseignement et de recherche français ou étrangers, des laboratoires publics ou privés. 


\title{
Magnetic ordering in the new ternary stannide $\mathrm{U}_{3} \mathrm{Rh}_{4} \mathrm{Sn}_{13}$
}

\author{
F. Mirambet ${ }^{\text {a }}$, B. Chevalier ${ }^{\text {a }}$, L. Fournes ${ }^{\text {a }}$, M.J. Besnus ${ }^{\text {b }}$, P. Gravereau ${ }^{\text {a }}$ \\ and J. Etourneau ${ }^{\text {a }}$ \\ ${ }^{a}$ Laboratoire de Chimie du Solide du CNRS, 351 cours de la Libération, 33405 Talence Cedex, France \\ ${ }^{b}$ IPCMS, GEMME, 3 rue de l'Université, 67084 Strasbourg, France
}

\begin{abstract}
$\mathrm{U}_{3} \mathrm{Rh}_{4} \mathrm{Sn}_{13}$ melts noncongruently and crystallizes in the cubic $\mathrm{Yb}_{3} \mathrm{Rh}_{4} \mathrm{Sn}_{13}$-type structure with $a=9.6416 \dot{\mathrm{A}}$. Magnetic, electrical, specific heat measurements and a ${ }^{119} \mathrm{Sn}$ Mössbauer spectroscopy study reveal that this stannide undergoes a magnetic transition near $17.5 \mathrm{~K}$. At low temperature, $\mathrm{U}_{3} \mathrm{Rh}_{4} \mathrm{Sn}_{13}$ shows an enhanced electronic specific heat coefficient $\left(\gamma_{0}=0.225 \mathrm{~J} / \mathrm{K}^{2} \mathrm{U}\right.$ atom) as observed in magnetically ordered heavy fermions compounds. In addition below the magnetic transition temperature a broadening of the two quadrupole splitting of the Mössbauer spectrum indicates clearly the presence of a hyperfine field at the $\mathrm{Sn}$ sites. $\mathrm{U}_{3} \mathrm{Rh}_{4} \mathrm{Sn}_{13}$ exhibits a magnetic ordering temperature that is much higher than those already observed for similar stannides containing rare earths.
\end{abstract}

\section{Introduction}

The ternary rare earth silicides, germanides and stannides with formulae $M_{3} T_{4} X_{13}(M=Y$, $\mathrm{Sc}, \mathrm{Ca}, \mathrm{Sr}, \mathrm{Th}$ or rare earth, $\mathrm{T}=3 \mathrm{~d}, 4 \mathrm{~d}$ or $5 \mathrm{~d}$ transition element and $\mathrm{X}=\mathrm{Si}, \mathrm{Ge}$ or $\mathrm{Sn}$ ) have been shown to exhibit very exciting physical properties such as for instance superconductivity or interplay between magnetic ordering and superconductivity [1-4]. These compounds crystallize in the cubic $\mathrm{Yb}_{3} \mathrm{Rh}_{4} \mathrm{Sn}_{13}$-type or in a derived structure depending on the size of both $\mathrm{M}$ and $\mathrm{T}$ atoms. For example, two different structures (I and $I^{\prime}$ ) have been found for the $M_{3} \mathrm{Rh}_{4} \mathrm{Sn}_{13}$ stannide series [5]. Phase $I$ is cubic $\left(a_{\mathrm{I}} \approx 9.7 \dot{\mathrm{A}}\right)$ and exists only for $\mathrm{M}=\mathrm{Eu}, \mathrm{Yb}, \mathrm{Ca}, \mathrm{Sr}$ and $\mathrm{Th}$ whereas the phase I' which is prepared only for $\mathbf{M}=\mathbf{L a} \rightarrow \mathrm{Gd}$ shows a tetragonal distortion of the phase I.

Recently we have reported the existence of the uranium-based ternary germanides $\mathrm{U}_{3} \mathrm{~T}_{4} \mathrm{Ge}_{13}$ with

Correspondence to: Dr. B. Chevalier, Laboratoire de Chimie du Solide du CNRS, 351 cours de la Libération, 33405 Talence Cedex, France.
$\mathrm{T}=\mathrm{Ru}, \mathrm{Os}, \mathrm{Rh}$ and $\mathrm{Ir}$ [6]. These compounds exhibit interesting physical properties, as for instance $\mathrm{U}_{3} \mathrm{Rh}_{4} \mathrm{Ge}_{13}$ which orders antiferromagnetically at $22 \mathrm{~K}$ and shows a metamagnetic transition with a hysteresis phenomena at lower temperatures. We have attempted to extend this family by preparing the $\mathrm{U}_{3} \mathrm{~T}_{4} \mathrm{Sn}_{13}$ stannides. In this paper, are reported the structural and magnetic properties of $\mathrm{U}_{3} \mathrm{Rh}_{4} \mathrm{Sn}_{13}$ investigated by $\mathrm{X}$-ray diffraction, magnetic and specific heat measurements and also by ${ }^{119} \mathrm{Sn}$ Mössbauer spectroscopy.

\section{Experimental procedure}

Stoichiometric $\mathrm{U}_{3} \mathrm{Rh}_{4} \mathrm{Sn}_{13}$ compound has been prepared by direct melting of the pure elements in an induction levitation furnace under a purified argon atmosphere. Then the sample has been annealed in a quartz tube at $800^{\circ} \mathrm{C}$ under vacuum for two weeks.

The resulting product has been characterized by X-ray powder diffraction using a Guinier camera ( $\mathrm{CuK} \alpha$ radiation) and its both composition and chemical homogeneity have been checked by 
microprobe analysis. The structure of $\mathrm{U}_{3} \mathrm{Rh}_{4} \mathrm{Sn}_{13}$ has been determined from X-ray powder diffraction data collected on a Philips PW 1050 diffractometer using a Bragg-Brentano geometry with a copper target and a take off angle of $6^{\circ}$. The powder diffraction patterns have been scanned in steps of $0.02^{\circ}(2 \theta)$ from $17^{\circ}$ to $110^{\circ}$ with a constant counting time of $40 \mathrm{~s}$.

Magnetization measurements have been carried out between 4.2 and $300 \mathrm{~K}$ using both a pendulum susceptometer and a SQUID magnetometer. The specific heat has been measured using a standard semiadiabatic heat-pulse method from 1.4 to $40 \mathrm{~K}$. The ${ }^{119} \mathrm{Sn}$ Mössbauer measurements have been performed between 4.2 and 300 $\mathrm{K}$ using a $\mathrm{CaSnO}_{3}$ source and a conventional constant acceleration spectrometer. The isomer shifts have been quoted relative to $\mathrm{CaSnO}_{3}$ at room temperature.

\section{Results and discussion}

Both X-ray diffraction and microprobe analysis reveal that the melted and quenched sample corresponding to $\mathrm{U}_{3} \mathrm{Rh}_{4} \mathrm{Sn}_{13}$ stoichiometry is indeed a mixture containing $\mathrm{USn}_{3}$ and $\mathrm{URhSn}$ as major components. But after annealing at $800^{\circ} \mathrm{C}$, the obtained product is a single phase and its composition checked by microprobe analysis confirm the existence of the new ternary stannide $\mathrm{U}_{3} \mathrm{Rh}_{4} \mathrm{Sn}_{13}$.

The X-ray powder pattern of $\mathrm{U}_{3} \mathrm{Rh}_{4} \mathrm{Sn}_{13}$ can be indexed on the basis of a primitive cubic unit
Table 1

Atomic positions and isotropic thermal agitation factors for $\mathrm{U}_{3} \mathrm{Rh}_{4} \mathrm{Sn}_{13}$. The standard deviations are given in brackets

\begin{tabular}{lrllll}
\hline Atom & Site & \multicolumn{2}{c}{ Atomic position } & $\begin{array}{l}B_{\text {eq }} \\
(\dot{\mathrm{A}})^{2}\end{array}$ \\
\cline { 3 - 5 } 1 & & $x$ & $y$ & $z$ & $0.58(3)$ \\
\hline $\mathrm{U}$ & $6 \mathrm{~d}$ & $1 / 4$ & $1 / 2$ & 0 & $0.48(6)$ \\
$\mathrm{Rh}$ & $8 \mathrm{e}$ & $1 / 4$ & $1 / 4$ & $1 / 4$ & $2.73(15)$ \\
$\mathrm{Sn}(1)$ & $2 \mathrm{a}$ & 0 & 0 & 0 & $1.54(4)$ \\
$\mathrm{Sn}(2)$ & $24 \mathrm{k}$ & 0 & $0.3081(2)$ & $0.1527(2)$ & 1.06 \\
\hline
\end{tabular}

cell $(a=9.6416 \dot{\mathrm{A}})$ corresponding to $\mathrm{Yb}_{3} \mathrm{Rh}_{4}$ $\mathrm{Sn}_{13}$-type structure [7]. The $\mathrm{X}$-ray powder data have been analyzed by means of the Rietveld profile refinement method. The atomic positions determined from this procedure are given in table 1. After refinement the reliability factor $R_{\mathrm{I}}$ has a value of 0.091 .

It is worthwhile noting that so far no ternary stannide corresponding to the $\mathrm{M}_{3} \mathrm{Rh}_{4} \mathrm{Sn}_{13}$ formulae has been prepared with rare earths (RE) having an atomic radius comparable to that of uranium. For example, with $\mathrm{RE}=\mathrm{Ho} \rightarrow \mathrm{Lu}$ another ternary stannide $\mathrm{SnRE}_{4} \mathrm{Rh}_{6} \mathrm{Sn}_{18}$ is characterized [5]. Thus the existence of the $\mathrm{M}_{3} \mathrm{Rh}_{4} \mathrm{Sn}_{13}$ is strongly influenced by both the size and the oxydation state of the $M$ element. The $\mathrm{Yb}_{3} \mathrm{Rh}_{4}$ $\mathrm{Sn}_{13}$-type structure is adopted only by ternary stannides containing divalent $\left(\mathrm{Eu}^{2+}, \mathrm{Yb}^{2+}, \mathrm{Ca}^{2+}\right.$ or $\mathrm{Sr}^{2+}$ ) or tetravalent $\left(\mathrm{Th}^{4+}\right) \mathrm{M}$ elements. This result suggests that the valence of uranium could be different from three in $\mathrm{U}_{3} \mathrm{Rh}_{4} \mathrm{Sn}_{13}$.

In the $\mathrm{Yb}_{3} \mathrm{Rh}_{4} \mathrm{Sn}_{13}$-type structure, the tin atoms occupy two different crystallographic sites

Table 2

Selected interatomic distances in $\mathrm{USn}_{3}, \mathrm{URh}_{3}, \mathrm{URhSn}$ and $\mathrm{U}_{3} \mathrm{Rh}_{4} \mathrm{Sn}_{13}$

\begin{tabular}{|c|c|c|c|c|c|c|c|}
\hline \multirow[t]{2}{*}{ Compound } & \multirow{2}{*}{$\begin{array}{l}\text { Structure } \\
\text { type }\end{array}$} & \multicolumn{4}{|c|}{ Distance $(\AA)$} & & \multirow[t]{2}{*}{ Ref } \\
\hline & & $\overline{\mathrm{U}-\mathrm{U}}$ & U-Rh & & $\mathrm{U}-\mathrm{Sn}$ & & \\
\hline $\mathrm{U}_{3} \mathrm{Rh}_{4} \mathrm{Sn}_{13}$ & $\mathrm{Yb}_{3} \mathrm{Rh}_{4} \mathrm{Sn}_{13}$ & 4.821 & $3.409 \times 4$ & $\begin{array}{l}\text { U-Sn(1) } \\
5.390 \times 6\end{array}$ & & $\begin{array}{l}U-\operatorname{Sn}(2) \\
3.376 \times 8 \\
3.395 \times 4\end{array}$ & a) \\
\hline $\begin{array}{l}\mathrm{USn}_{3} \\
\mathrm{URh}_{3} \\
\text { URhSn }\end{array}$ & $\begin{array}{l}\mathrm{AuCu}_{3} \\
\mathrm{AuCu}_{3} \\
\mathrm{Fe}_{2} \mathrm{P}\end{array}$ & $\begin{array}{l}4.626 \\
3.991 \\
3.832\end{array}$ & $\begin{array}{l}2.822 \\
3.071 \times 1 \\
2.980 \times 4\end{array}$ & & $\begin{array}{l}3.134 \times 2 \\
3.343 \times 4\end{array}$ & & $\begin{array}{l}{[8]} \\
{[8]} \\
{[9]}\end{array}$ \\
\hline
\end{tabular}

a) This work. 
(table 1). The $\mathrm{Rh}$ atoms are situated inside trigonal prisms formed by six $\mathrm{Sn}(2)$ atoms [7]. The $\mathrm{RhSn}_{6}(2)$ prisms, share corners, to form a threedimensional network, which generates icosahedral and cubooctahedral sites containing respectively $\mathrm{Sn}(1)$ and $\mathrm{Yb}$ or $\mathrm{U}$ atoms. The large $\mathrm{U}-\mathrm{U}$ interatomic distances in $\mathrm{U}_{3} \mathrm{Rh}_{4} \mathrm{Sn}_{13}\left(d_{\mathrm{U}-\mathrm{U}}=\right.$ $4.821 \dot{\mathrm{A}})$ are far above the Hill's limit $(3.50 \dot{\mathrm{A}})$ below which the uranium $5 \mathrm{f}$ orbitals of neighbouring sites can overlap (table 2). The U-Sn(2) distances which are shorter than the U-Sn(1) ones, are nevertheless larger than those observed in $\mathrm{USn}_{3}$ (table 2). [8]. In the same way, the U-Rh distances in $U_{3} R_{4} S_{13}$ stannide are much larger than those existing in $U_{R h}$. The strength of the hybridization between the $5 f$ orbitals and the electronic states of the ligand ( $\mathrm{Rh}$ or $\mathrm{Sn}$ ) must be reduced in $U_{3} R_{4} S_{13}$ in comparison with that observed in both $\mathrm{USn}_{3}$ and $\mathrm{URh}_{3}$ for which no magnetic order is detected: $\mathrm{URh}_{3}$ shows a Pauli paramagnetism behaviour whereas $\mathrm{USn}_{3}$ is a highly enhanced paramagnet. On the other hand, the average distances $\overline{\mathrm{U}-\mathrm{Sn}}$ and $\overline{\mathrm{U}-\mathrm{Rh}}$ observed in $\mathrm{U}_{3} \mathrm{Rh}_{4} \mathrm{Sn}_{13}$ are greater than those determined in URhSn which orders ferromagnetically at low temperature [9].

The magnetic susceptibility $\chi_{\mathrm{m}}$ of $\mathrm{U}_{3} \mathrm{Rh}_{4} \mathrm{Sn}_{13}$ has been analyzed between $20 \mathrm{~K}$ and room temperature on the basis of a modified Curie-Weiss law (fig. 1):

$\chi_{\mathrm{m}}=\chi_{0}+C_{\mathrm{m}} /\left(T-\Theta_{\mathrm{p}}\right)$,

where $\chi_{0}$ is a temperature independent term, $C_{\mathrm{m}}$ the Curie constant and $\Theta_{p}$ the paramagnetic Curie temperature. The values of $C_{\mathrm{m}}=2.123 \mathrm{emu} / \mathrm{mol}$, $\theta_{\mathrm{p}}=+1.8 \mathrm{~K}$ and $\chi_{0}=3.329 \times 10^{-3} \mathrm{emu} / \mathrm{mol}$ have been deduced from the susceptibility measurements by a least squares method. The effective magnetic moment ( $\mu_{\text {eff }}=2.38 \mu_{\mathrm{B}} / \mathrm{U}$ atom) is close to that both calculated for uranium in the $5 f^{1}$ state and reported for $\mathrm{USn}_{3}\left(\mu_{\text {eff }}=2.4 \mu_{\mathrm{B}} / \mathrm{U}\right.$ atom) [10]. A peak observed in the thermal dependence of the magnetization curve of $\mathrm{U}_{3} \mathrm{Rh}_{4}$ $\mathrm{Sn}_{13}$ centered at around $18 \mathrm{~K}$, suggests the occurrence of an antiferromagnetic ordering (fig. 2).

In the temperature range from 150 to $270 \mathrm{~K}$, the electrical resistivity of $U_{3} R_{4} S_{13}$ weakly

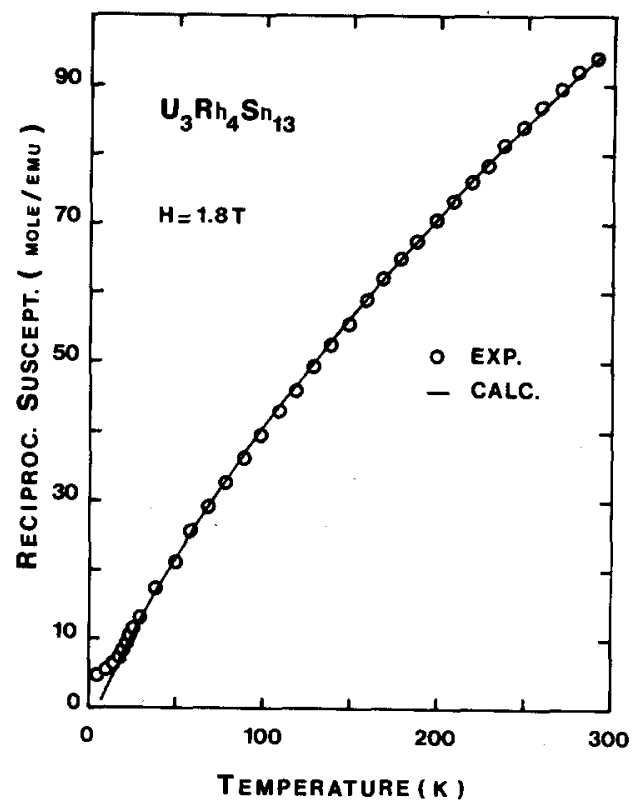

Fig. 1. Temperature dependence of the reciprocal magnetic susceptibility of $\mathrm{U}_{3} \mathrm{Rh}_{4} \mathrm{Sn}_{13}$.

varies by showing a slight increase with decreasing temperature (fig. 3). Then the resistivity begins to decrease from about $150 \mathrm{~K}$, showing a

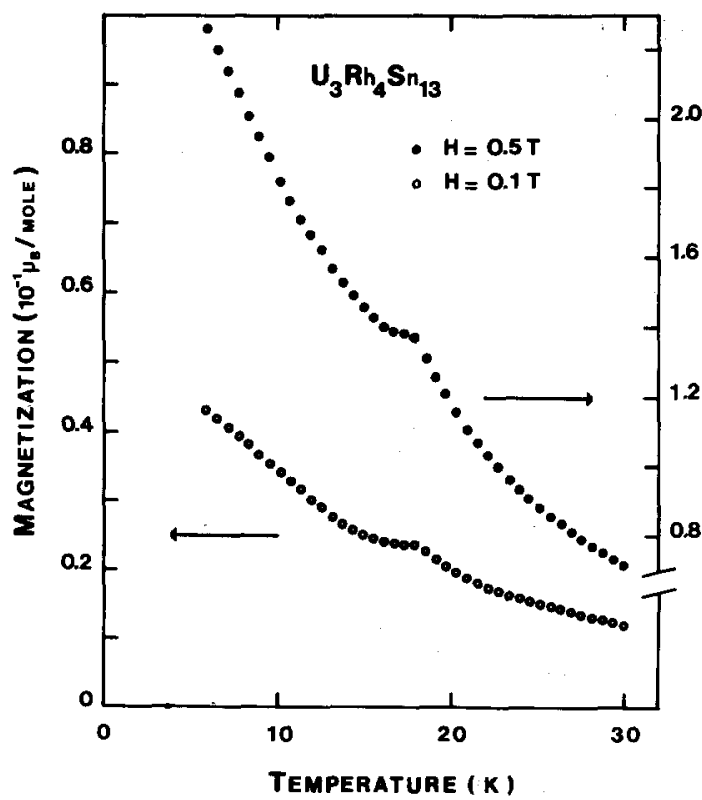

Fig. 2. Temperature dependence below $30 \mathrm{~K}$ of the magnetization for $\mathrm{U}_{3} \mathrm{Rh}_{4} \mathrm{Sn}_{13}$ in two different applied fields. 


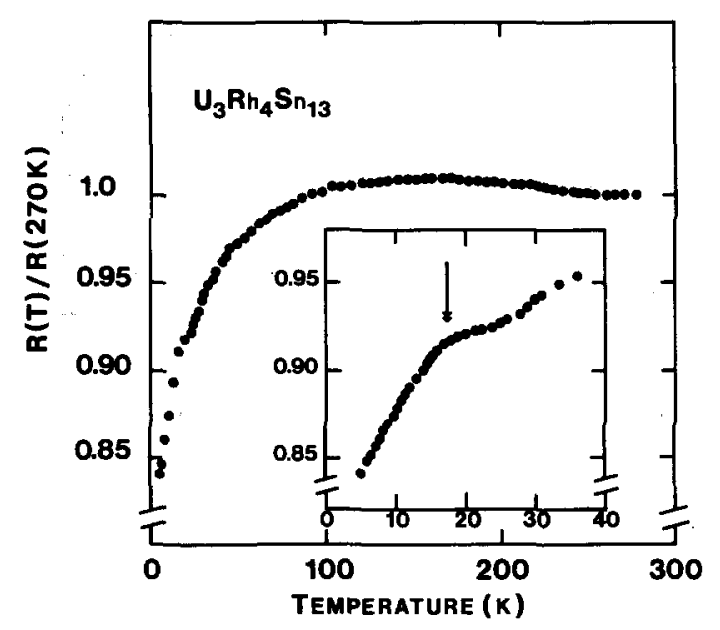

Fig. 3. Temperature dependence of the electrical resistivity normalized at $270 \mathrm{~K}$ for $\mathrm{U}_{3} \mathrm{Rh}_{4} \mathrm{Sn}_{13}$. Arrows ( $\downarrow$ ) indicate: the magnetic transition temperature.

shoulder centered around $18-22 \mathrm{~K}$, and finally decreases very rapidly below $18 \mathrm{~K}$. The occurrence of such a behaviour in the thermal dependence of the resistivity is typical of a Kondo effect in the presence of a crystal field splitting in the $5 f$ (or $4 \mathrm{f}$ ) systems [11]. Thus the broad maximum which appears near $150 \mathrm{~K}$ results from the crystalline field effect and the peak which occurs at $18 \mathrm{~K}$ is the signature of the magnetic ordering.

Specific heat measurements performed in the 1.4-25 $\mathrm{K}$ range are shown in fig. 4 . The magnetic transition is discerned through a small, but dis-

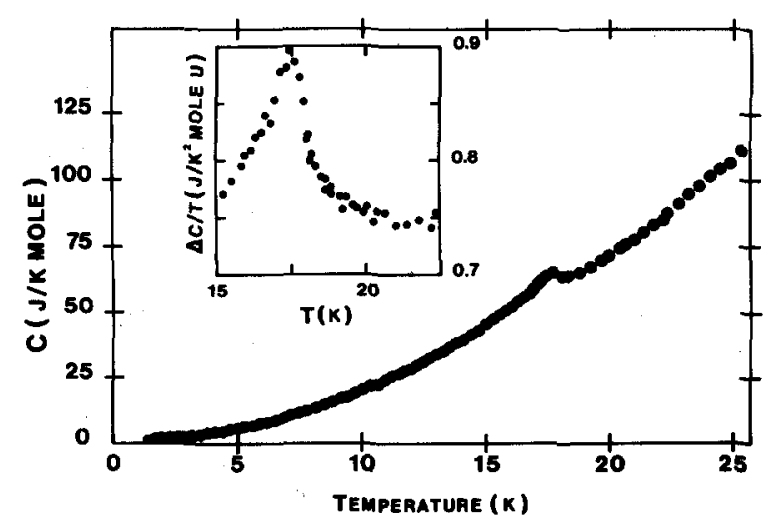

Fig. 4. Temperature dependence of the specific heat for $\mathrm{U}_{3} \mathrm{Rh}_{4} \mathrm{Sn}_{13}$. Inset: $\Delta C / T$ jump observed at the magnetic transition temperature.

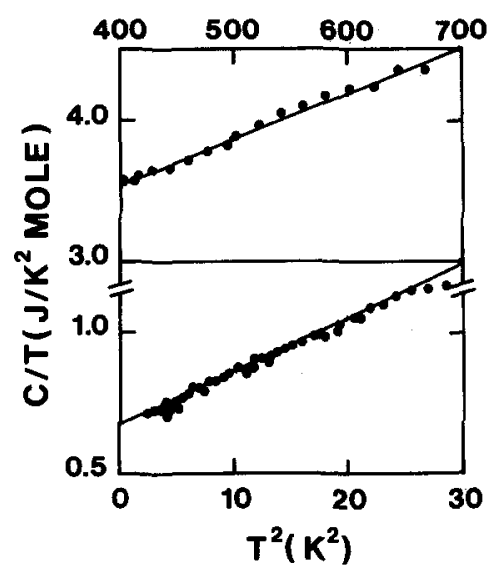

Fig. 5. $C / T$ versus temperature for $\mathrm{U}_{3} \mathrm{Rh}_{4} \mathrm{Sn}_{13}$ above $(T>20$ $\mathrm{K})$ and below its magnetic transition temperature $(T<5.5 \mathrm{~K})$.

tinct anomaly which peaks at $\approx 17.5 \mathrm{~K}$ in agreement with magnetic and electrical results. The behaviour in the temperature region above the transition is illustrated in fig. 5 by a $C / T$ vs. $T^{2}$ representation. Extrapolation of the apparently simple $\gamma_{\mathrm{p}} T+\beta_{\mathrm{p}} T^{3}$ behaviour yields a large linear term $\gamma_{\mathrm{p}}=0.75 \mathrm{~J} / \mathrm{K}^{2} \mathrm{U}$ atom with $\beta_{\mathrm{p}}=3.225 \times$ $10^{-3} \mathrm{~J} / \mathrm{K}^{4} \mathrm{~mol}$. In the magnetically ordered state, below about $5 \mathrm{~K}$ (fig. 5), the experimental data are again consistent with a temperature dependence given by $\gamma_{0} T+\beta_{0} T^{3}$, with an extrapolated $\gamma_{0}$ value of $0.225 \mathrm{~J} / \mathrm{K}^{2} \mathrm{U}$ atom and a large $\beta_{0}$ value of $1.875 \times 10^{-2} \mathrm{~J} / \mathrm{K}^{4} \mathrm{~mol}$. The $\gamma_{0}$ value appears as remarkably enhanced like in magnetically ordered heavy-fermion systems as for instance $\mathrm{UCd}_{11}\left(\gamma_{0}=0.250 \mathrm{~J} / \mathrm{K}^{2} \mathrm{U}\right.$ atom $)$ which orders antiferromagnetically below $5 \mathrm{~K}$ [12]. Furthermore we can note that at low temperatures, at least in the explored $T$-range, the specific heat varies as $T^{3}$ which is the form expected for antiferromagnetic magnons. In the inset of the fig. 4 , we have plotted the ratio of the contribution excess $\Delta C$ (obtained by subtracting the cubic $\beta T^{3}$ term corresponding to $T>20 \mathrm{~K}$ ) over the temperature. The relative discontinuity at the phase transition $\Delta C / T_{\mathrm{m}}$ amounts to $0.14 \mathrm{~J} / \mathrm{K}^{2} \mathrm{U}$ atom which corresponds to a jump $\Delta C /\left(\gamma_{p}-\right.$ $\left.\gamma_{0}\right) T_{\mathrm{m}}$ of only $\approx 0.26$. This small value points towards reduced magnetic moments and also suggests that some heavy electrons survive in the magnetic state. In this view, the part of the Fermi 


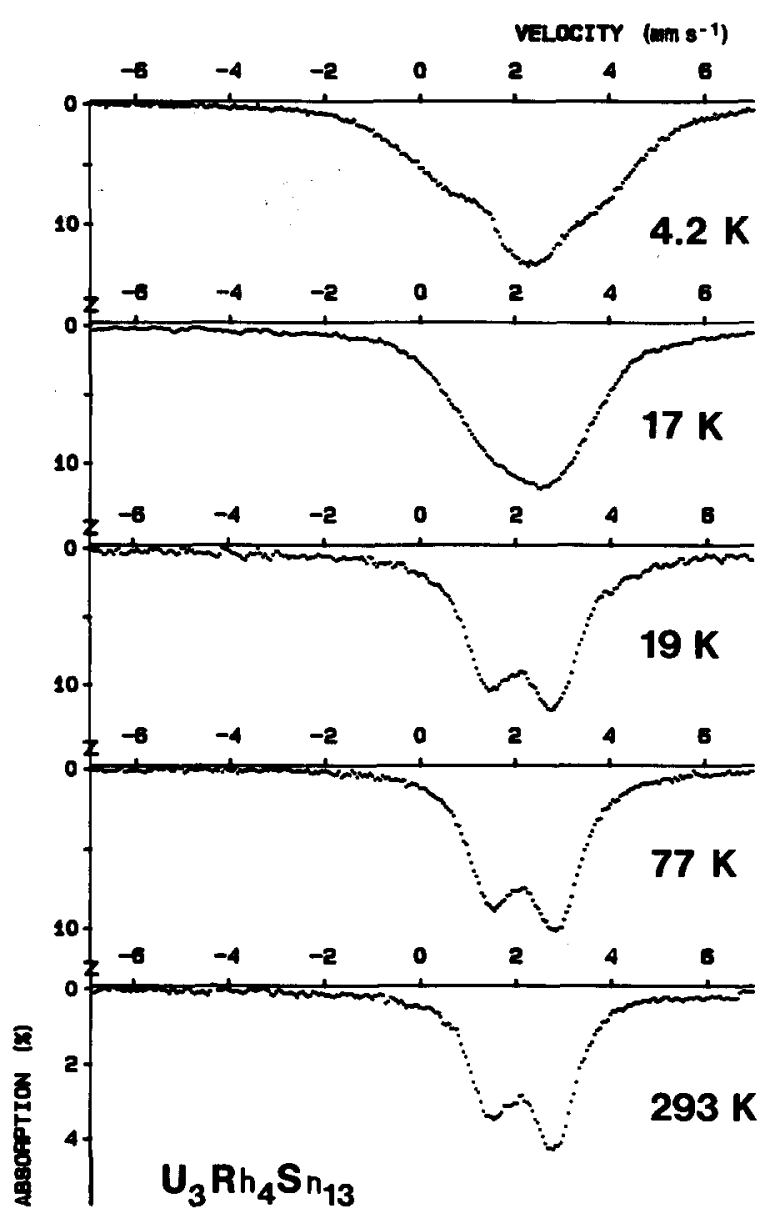

Fig. 6. ${ }^{119} \mathrm{Sn}$ Mössbauer spectra for $\mathrm{U}_{3} \mathrm{Rh}_{4} \mathrm{Sn}_{13}$ at various temperatures.

surface removed by the magnetic ordering may be estimated as $\approx 70 \%$ from the fractional change in the temperature linear terms, $\left(\gamma_{\mathrm{p}}-\gamma_{0}\right) / \gamma_{\mathrm{p}}$, a value of the same order magnitude as that observed in other known magnetically ordered heavy-fermion systems [11].

The ${ }^{119} \mathrm{Sn}$ Mössbauer spectrum of $\mathrm{U}_{3} \mathrm{Rh}_{4} \mathrm{Sn}_{13}$ measured at various temperatures are shown in fig. 6. At room temperature, this spectrum has been fitted by two quadrupole doublets corresponding to $S n$ in $2 \mathrm{a}(\mathrm{Sn}(1))$ and $24 \mathrm{k}(\mathrm{Sn}(2))$ sites. The assignment of the doublets to the crystallographic sites has been done with respect to their relative intensities. The values of the isomer shift (IS) and of the quadrupole splitting (QS) derived from this procedure indicate a large chemical difference between the two $\mathrm{Sn}$ sites. The IS values are $(2.55 \pm 0.07)$ and $(2.09 \pm 0.02) \mathrm{mm} \mathrm{s}^{-1}$ and the QS ones are $(0.61 \pm 0.07)$ and $(1.34 \pm$ $0.02) \mathrm{mm} \mathrm{s}^{-1}$ for $\mathrm{Sn}(1)$ and $\operatorname{Sn}(2)$ respectively. The fact that the quadrupole splitting parameter of the $\operatorname{Sn}(1)$ atom is smaller than that observed for the $\operatorname{Sn}(2)$ one indicates a decrease of the electrical field gradient at the $\operatorname{Sn}(1)$ site. This result is in agreement with the fact that the $\overline{\mathrm{U}-\mathrm{Sn}(1)}$ average distance is greater than the $\overline{\mathrm{U}-\mathrm{Sn}(2)}$ one (table 2). Also, it is worth noting that the IS value for the $\mathrm{Sn}(1)$ site is greater than that observed for the $\operatorname{Sn}(2)$ site, thus showing an increase in the s electron density at the $\operatorname{Sn}(1)$ Mössbauer nuclei. Below $18 \mathrm{~K}$, the spectrum shows a clear broadening due to a magnetic hyperfine field which confirms the occurrence of a magnetic ordering in $\mathrm{U}_{3} \mathrm{Rh}_{4} \mathrm{Sn}_{13}$ (fig. 6). The spectrum at $T=4.2 \mathrm{~K}$ exhibits a small hyperfine field splitting implying that the Sn atoms see a small magnetic moment localized on uranium site. A detailed investigation of our ${ }^{119} \mathrm{Sn}$ Mössbauer study will be published soon.

\section{Conclusion}

The present results indicate that the $\mathrm{U}_{3} \mathrm{Rh}_{4}$ $\mathrm{Sn}_{13}$ compound orders magnetically around $17.5-$ $18 \mathrm{~K}$. From the specific heat measurements as well as Mössbauer spectroscopy the magnetic moment must be small. This allows us to propose $\mathrm{U}_{3} \mathrm{Rh}_{4} \mathrm{Sn}_{13}$ as a magnetically ordered heavyfermion system in which the magnetic properties can be qualitatively understood within the framework of a competition between the Kondo spin fluctuation and the oscillatory magnetic RKKY interaction [11]. On the other hand, we must mention that the magnetic ordering temperature of $U_{3} R_{4} S_{13}$ is greater than that determined for the isomorphous $\mathrm{Gd}_{3} \mathrm{Rh}_{4} \mathrm{Sn}_{13}$ compound which orders magnetically at $T_{\mathrm{m}}=11.2 \mathrm{~K}$ [4]. This observation which cannot be explained from simple De Gennes factor considerations shows that the magnetic interactions in $\mathrm{U}_{3} \mathrm{Rh}_{4} \mathrm{Sn}_{13}$ are not only RKKY type. This behaviour could be due to an unusually strong 5f-conduction electrons hybridization. 


\section{References}

[1] B. Lloret, B. Chevalier, P. Lejay and J. Etourneau, C.R. Acad. Sc. Paris 303 (1986) 1193.

[2] C.U. Segre, H.F. Braun and K. Yvon, in: Ternary Superconductors, eds. G.K. Shenoy, B.D. Dunlap and F.Y. Fradin (North-Holland, Amsterdam, 1981) p. 243.

[3] G. Venturini, M. Kanta, E. McRae, J.F. Mareché, B. Malaman and B. Roques, Mater. Res. Bull. 21 (1986) 1203.

[4] G.P. Espinosa, A.S. Cooper and H. Barz, Mater. Res. Bull. 17 (1982) 963.

[5] S. Miraglia, J.L. Hodeau, M. Marezio, C. Laviron, M. Ghedira and G.P. Espinosa, J. Solid State Chem. 63 (1986) 358.
[6] B. Lloret, B. Chevalier, P. Gravereau, B. Darriet and J. Etourneau, J. de Phys. 49 (1988) C8-487.

[7] J.M. Vandenberg, Mater. Res. Bull. 15 (1980) 835.

[8] D.D. Koelling, B.D. Dunlap and G.W. Crabtree, Phys. Rev. B 31 (1985) 4966.

[9] T.T.M. Palstra, G.J. Nieuwenhuys, R.F.M. Vlastuin, J. van der Berg, J.A. Mydosh and K.H.J. Buschow, J. Magn. Magn. Mater. 67 (1987) 331.

[10] C.L. Lin, L.W. Zhou, J.E. Crow and R.P. Guertin, J. Appl. Phys. 57 (1985) 3146.

[11] G.R. Stewart, Rev. Modern Phys. 56 (1984) 755.

[12] Z. Fisk, G.R. Stewart, J.O. Willis, H.R. Ott and F. Hullinger, Phys. Rev. B 30 (1984) 6360. 